\title{
Balancing Academic with Research: A Paradox
}

\author{
Madhab Lamsal
}

Affiliations:

Department of Biochemistry, B. P. Koirala Institute of Health Sciences, Dharan, Nepal.

Correspondence to:

Dr. Madhab Lamsal

Professor and Head

Department of Biochemistry

B. P. Koirala Institute of Health Sciences, Dharan, Nepal

Email: madhab.lamsal@bpkihs.edu

How to cite this article:

Lamsal M. Balancing Academic with Research: A Paradox. Ann. Clin. Chem. Lab. Med. 2016:2(1);1-2

DOI: http://dx.doi.org/10.3126/acclm.v2i1.14827

(C) 2016 Nepalese Association for Clinical Chemistry

\section{(c) (1) ()}

This work is licensed under a Creative Commons Attribution-ShareAlike 4.0 International License.
The job requirement in many health institutions and professional academic institutions stresses the need to contribute in three main aspects: academics, service and research. While it may have detailed guidelines for the academics and service components, there is no clear workings on the research and ambiguously stresses that one should do quality research and publish a quality findings that may directly benefit the subjects/populations under study. Moreover, it is given undue weightage in job stability and promotions.

Paradoxically, no one clearly emphasizes on the quality resources and the time that needs to be allotted for the research activities. Developing a research group at times becomes more challenging and less sustainable. Although much time is demanded to be invested on academics and service aspects, research, where no defined hours and inputs are mentioned, remains a yardstick of professional success and rewards.

Ideas are born but require recognition and continuous nurturing, providing optimum requisite thriving environment. Investing some time and other material resources to train in human resource development and capacity building will certainly add quality ingredients to scientific research and in the long run society will reap a good harvest. Not all research findings will immediately find its immediate appreciation and get published, but it may still contribute towards the fundamentals that will certainly lay grounds for bigger breakthrough research in due course of time. Hence, it should be considered as research and sole research.

In paucity of qualified human resources, or lack of ambient socio-political and professional commitment, a clear ground rule of research in Nepal is yet to set a full gear. Pastures remain greener on the other side that applies for our professional brain drain and intellectual poverty griping every aspects of higher and professional education.

The constraint bought in by the paucity of funding to research which doesn't seem to bear direct result to be translated into practice in 
medical field may divert many talented and potential researches away from medical research which in turn may create a void in the next generation researchers. In addition, the higher education and low prospects and undefined pay and working hours may divert the young and genius away from the research to alteration of professions. Thus, the stake holders should come forward with clear job prospects if the society is expecting a good breed of young talents. Therefore, encouraging the publication of findings based on ethical and quality research needs to be prioritized. A good balance should therefore be established among the academics, research and service components. 